\title{
Mastitis granulomatosa simulando cáncer de mama
}

\section{Rigoberto Gómez Gutiérrez, Henry Idrobo}

Hemato Oncólogos S.A., Cali (Valle del Cauca).

Contacto: rigobertogomezg@hotmail.com

Introducción y objetivos. La mastitis granulomatosa (MG) es una enfermedad inflamatoria benigna, infrecuente, criptogénica, que simula cáncer de mama (CM). Se describe caso de mujer premenopáusica con esta patología.

Materiales y métodos. Descripción de caso y literatura.

Resultados. Mujer, 30 años, dos embarazos, sin antecedentes, con tres meses de mastalgia, masa en mama derecha en crecimiento, multilobulada, con eritema nodoso en piernas. Ecografía mamaria: lesión nodular de 2,6 $\mathrm{cm}$, adenopatía de 1,3 cm ipsilateral. Biopsia por trucut: no malignidad, mastitis crónica. Tres meses después, ecografía muestra zona irregular heterogénea de 5,9 ×3,9 cm. Recibió antibioticoterapia por absceso posterior a biopsia, luego prednisona sin mejoría. Se descartó extensión de CM, tuberculosis, hepatitis, autoinmunidad, fiebre reumática. Cinco meses después, evolución tórpida, requirió cuadrantectomía. Patología: inflamación crónica granulomatosa con abscedación y fibrosis estromal. Evolución satisfactoria.

Conclusiones. Mujer premenopáusica con MG que simuló CM requiriendo cuadrantectomía; no se asoció a puerperio o lactancia, ni debutó con abscedación, como tampoco tuvo respuesta a esteroides.

\section{Reporte de caso: hallazgo de Cryptococcus spp. en aspirado de médula ósea con coloración de Wright}

\section{Miriam Beatriz Amaya Bernal, Yurany Duarte Torres, Javier Ignacio Godoy Barbosa, Óscar Iván Reyes Cortés}

Hospital Militar Central, Bogotá, D.C.

Contacto: oireyescortes@gmail.com

Introducción y objetivos. Los pacientes inmunocomprometidos con patologías como el virus de la inmunodeficiencia humana $(\mathrm{VIH})$ son susceptibles a adquirir fácilmente infecciones oportunistas, como el caso de este paciente de 23 años, $\mathrm{VIH+}$, tratado con HAART, quien presenta síntomas B acompañados de tos seca, dificultad respiratoria y pancitopenia.

Materiales y métodos. Se decide realizar estudio de médula ósea con la tinción usual de Wright.

Resultados. Muestra médula hipercelular con representación hematopoyética de todas las líneas, cambios megaloblásticos y diseritropoyéticos en las series mieloide y eritroide, respectivamente, acompañados de plasmocitos maduros. Se observan blastoconidias encapsuladas, redondas y ovaladas de 4-6 $\mu \mathrm{m}$ de diámetro, con pared gruesa refringente, algunas de ellas en gemación. Los anteriores hallazgos son compatibles con mieloptisis por Cryptococcus spp.

Conclusiones. Esta es la primera publicación que presenta la tinción de Wright como una coloración útil para la identificación de criptococos en material aspirado de médula ósea. 